Supporting information

\title{
Experimental data and modeling for viscosity and refractive index of aqueous mixtures with 2-(methylamino)ethanol (MAE) and aminoehtylethanolamine (AEEA)
}

Diwakar Pandey, Monoj Kumar Mondal*

Department of Chemical Engineering \& Technology, Indian Institute of Technology

(Banaras Hindu University), Varanasi - 221005, Uttar Pradesh, India

*E-mail: mkmonda113@yahoo.com Tel. No.: +919452196638; Fax:+91 5422368092

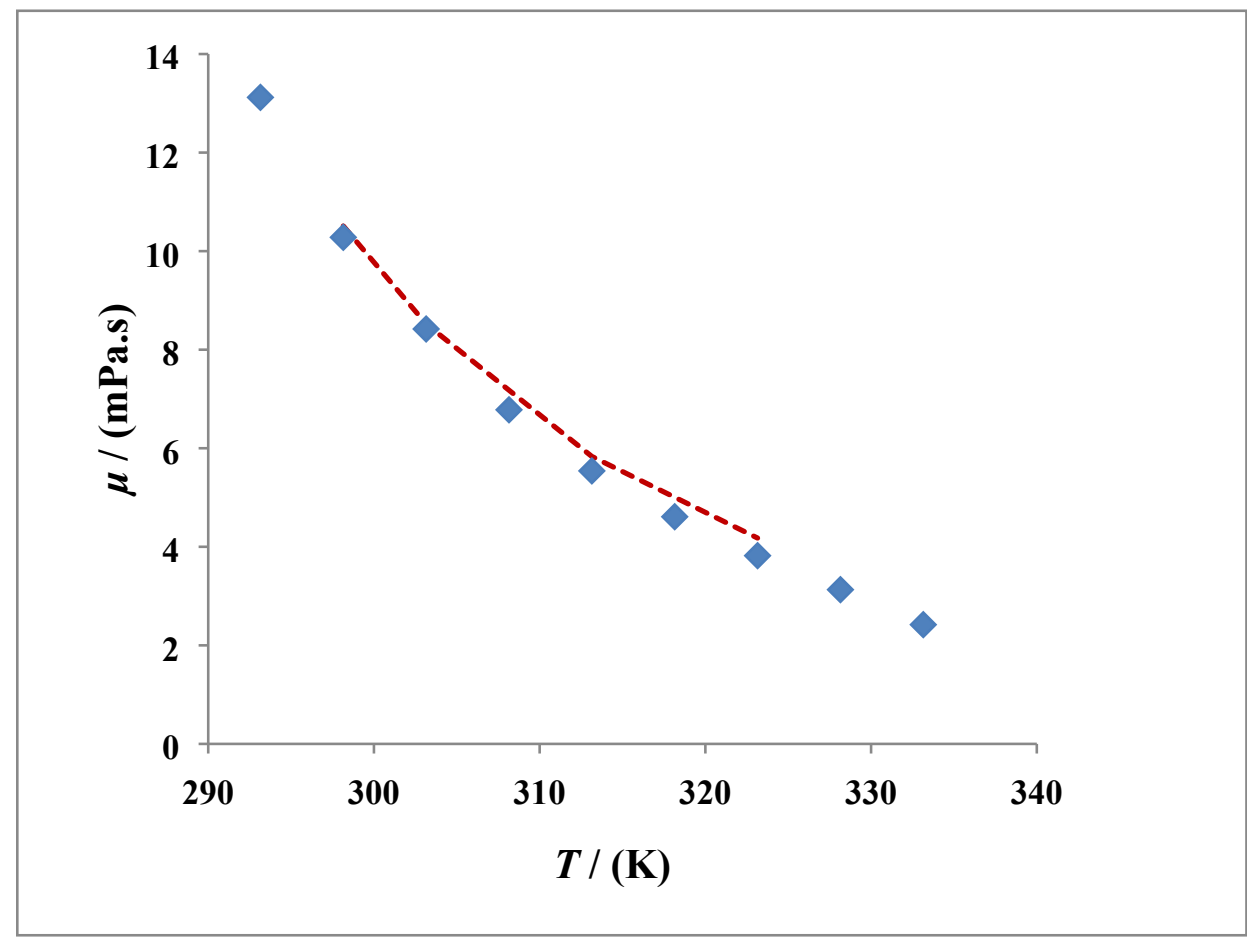

Figure S1. Viscosity of pure 2-(methylamino) ethanol (MAE) with temperature. Symbols are the experimental data in this work and dashed line from Li et al. (2007) ${ }^{17}$. 


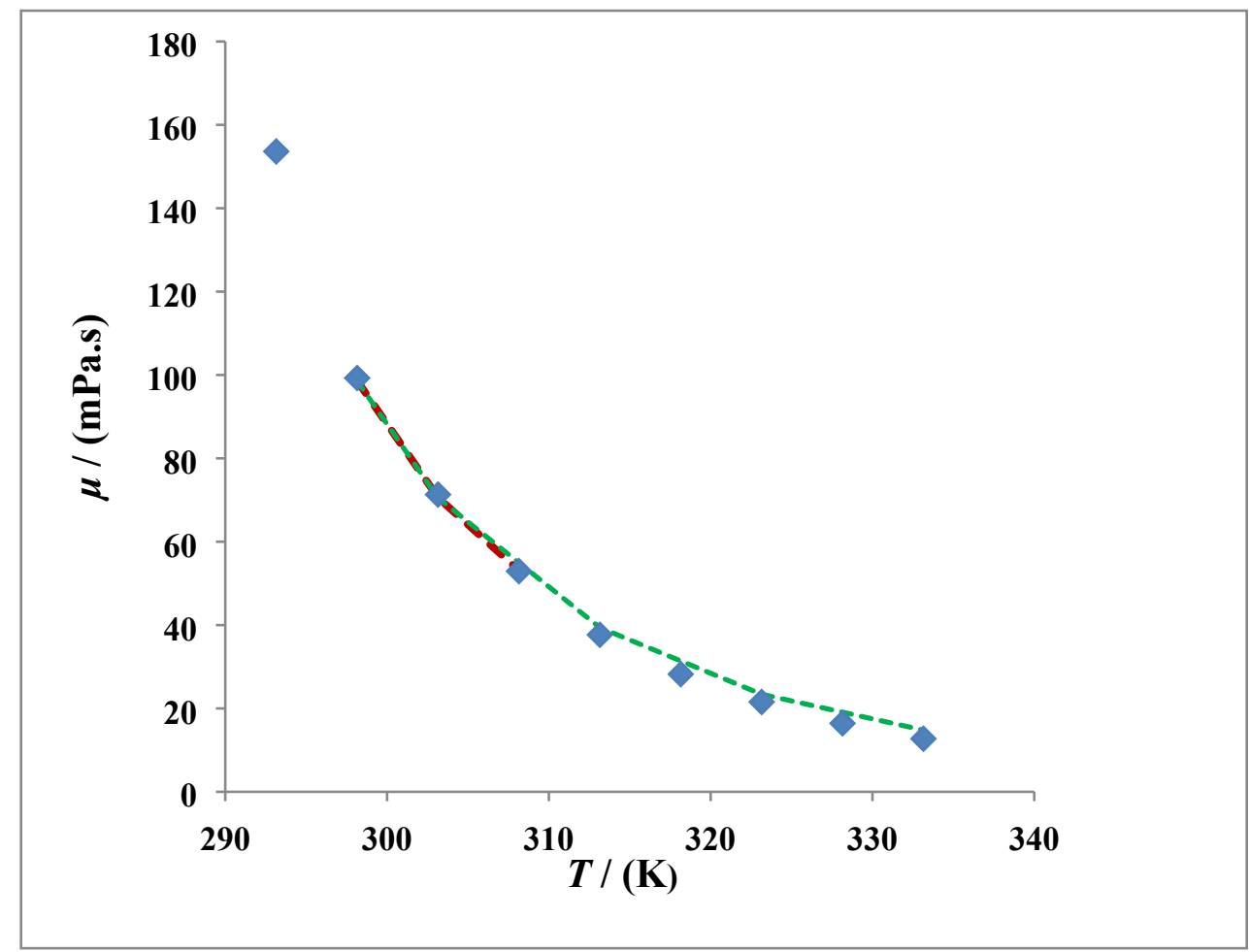

Figure S2. Viscosity of pure aminoehtylethanolamine (AEEA) with temperature. Symbols are the experimental data in this work and red dashed line from Moosavi et al. (2017) ${ }^{6}$, and green dashed line from Mundhwa et al. (2006) ${ }^{35}$. 


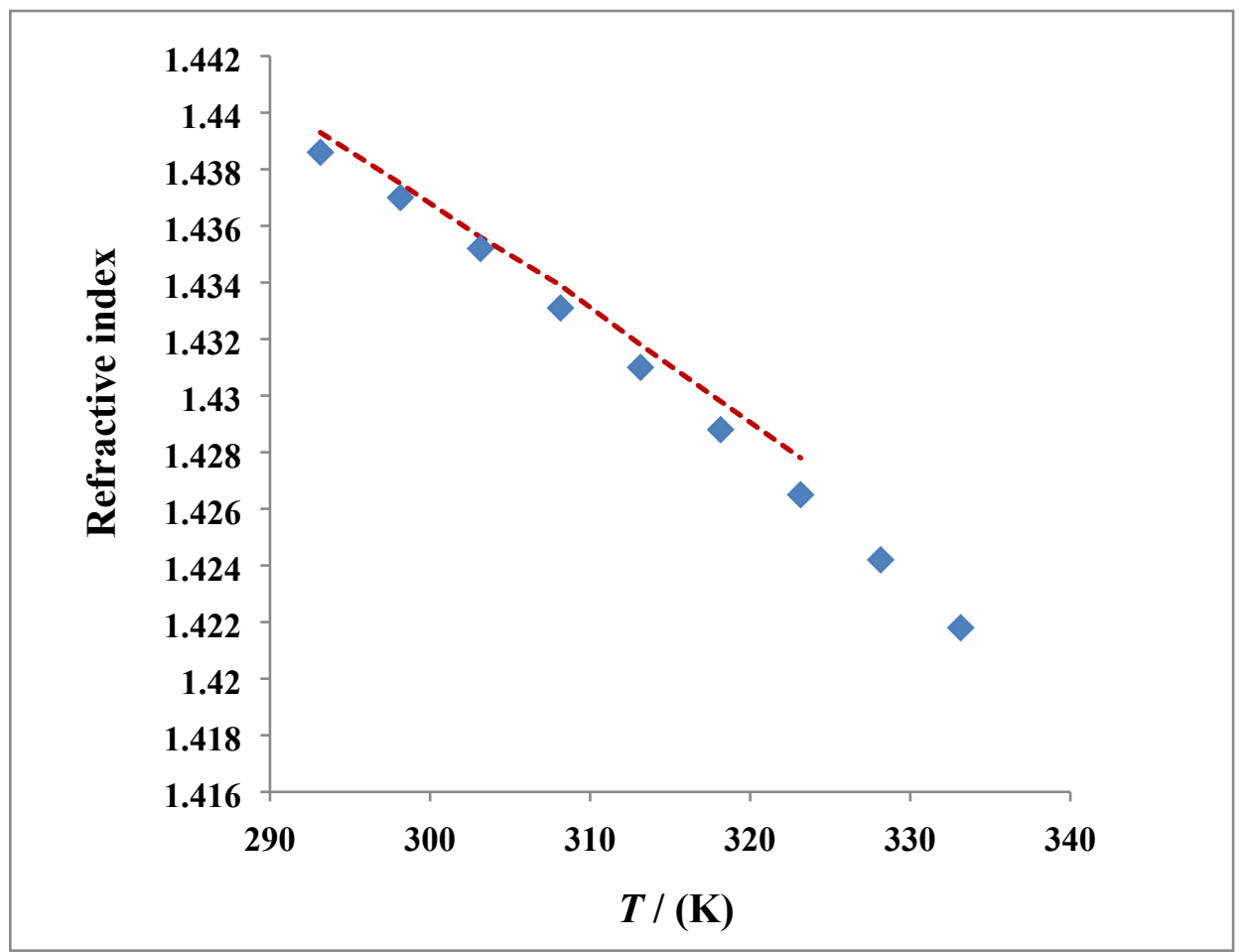

Figure S3. Refractive index of pure 2-(methylamino) ethanol (MAE) with temperature. Symbols are the experimental data in this work and dashed line from Li et al. (2007) ${ }^{17}$. 


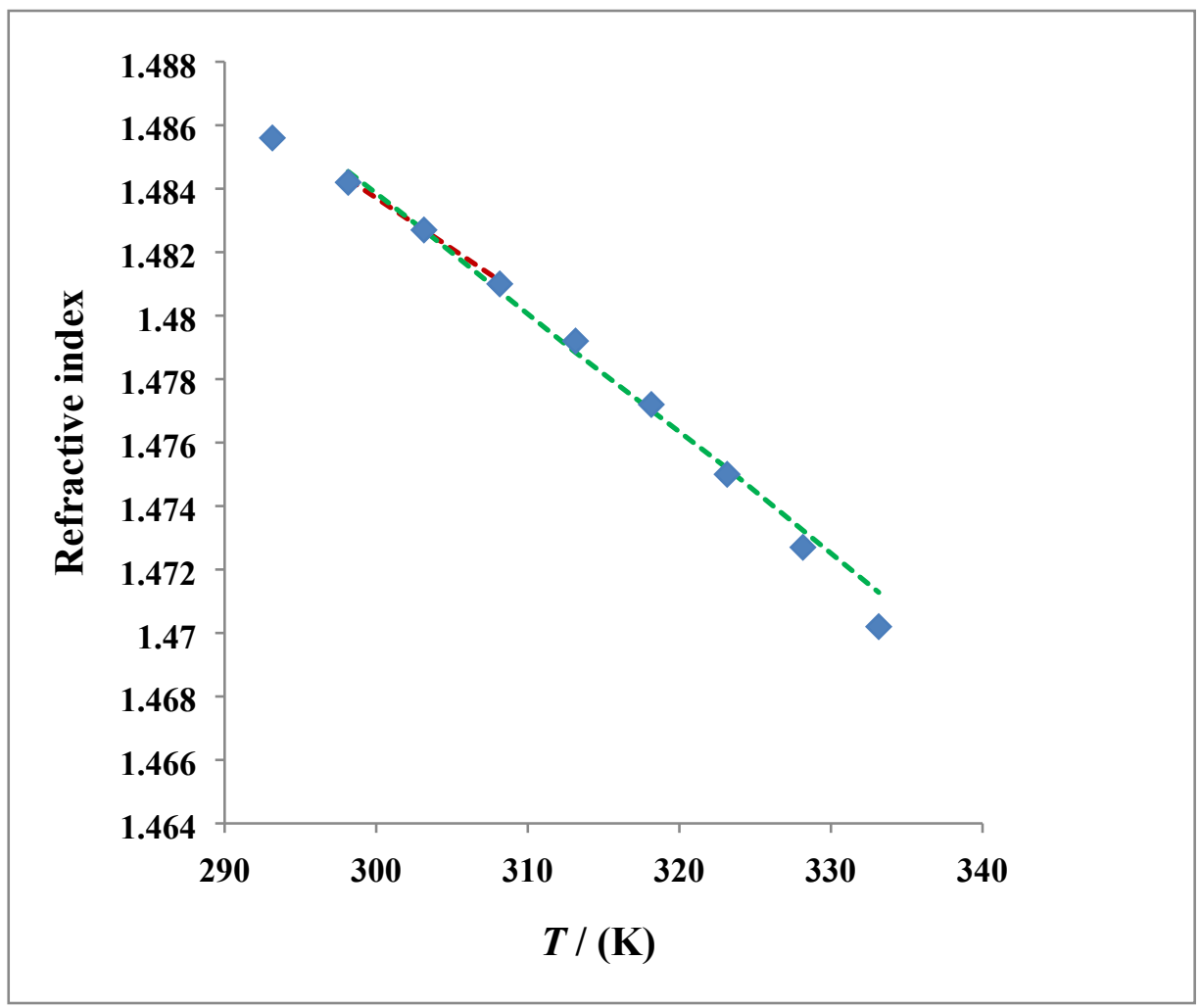

Figure S4. Viscosity of pure aminoehtylethanolamine (AEEA) with temperature. Symbols are the experimental data in this work and red dashed line from Moosavi et al. (2017) ${ }^{6}$, and green dashed line from Mundhwa et al. (2006) ${ }^{35}$. 


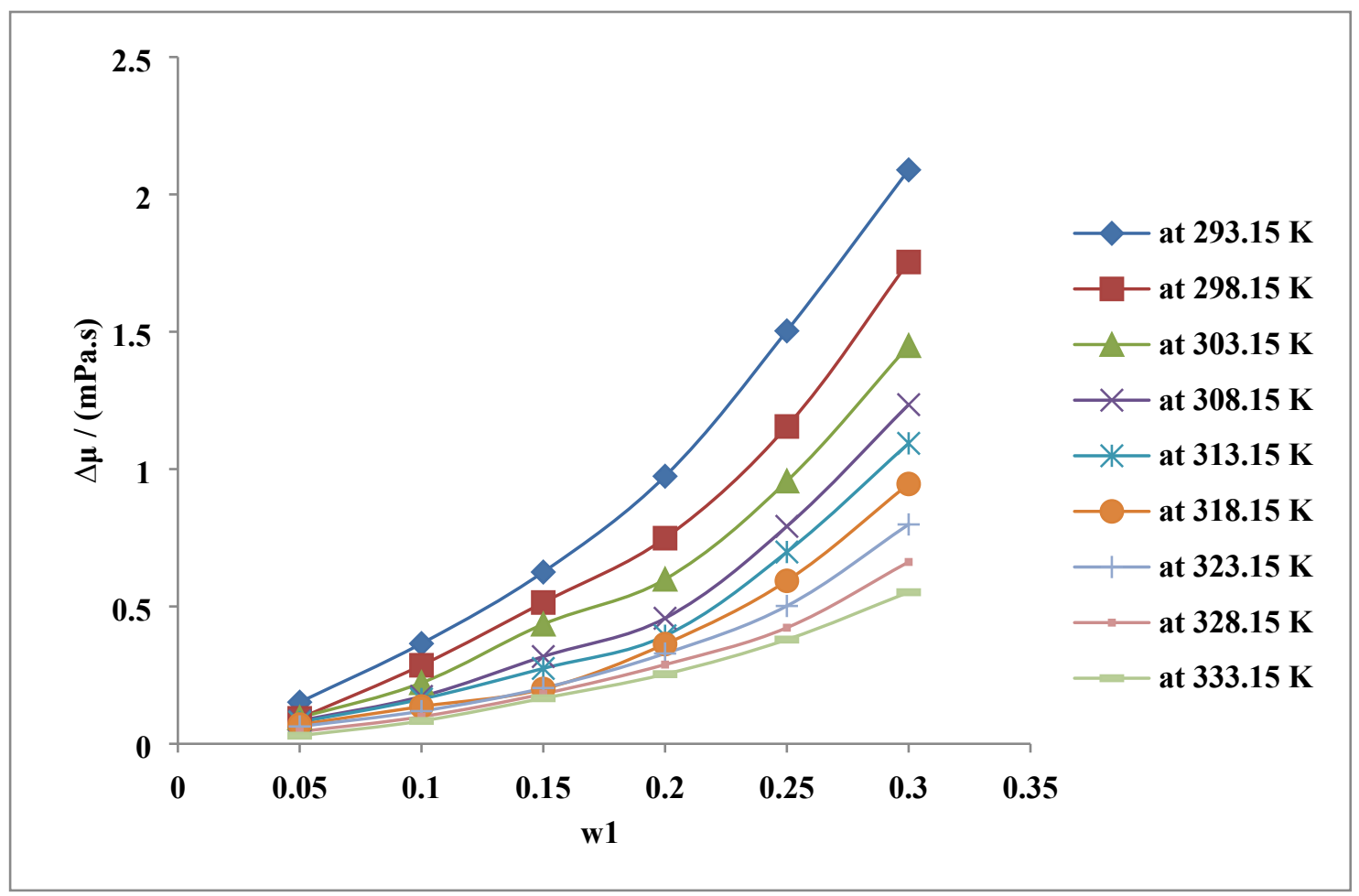

Figure S5. Variation of deviation in viscosity of MAE with a weight fraction of MAE in the aqueous mixture. 


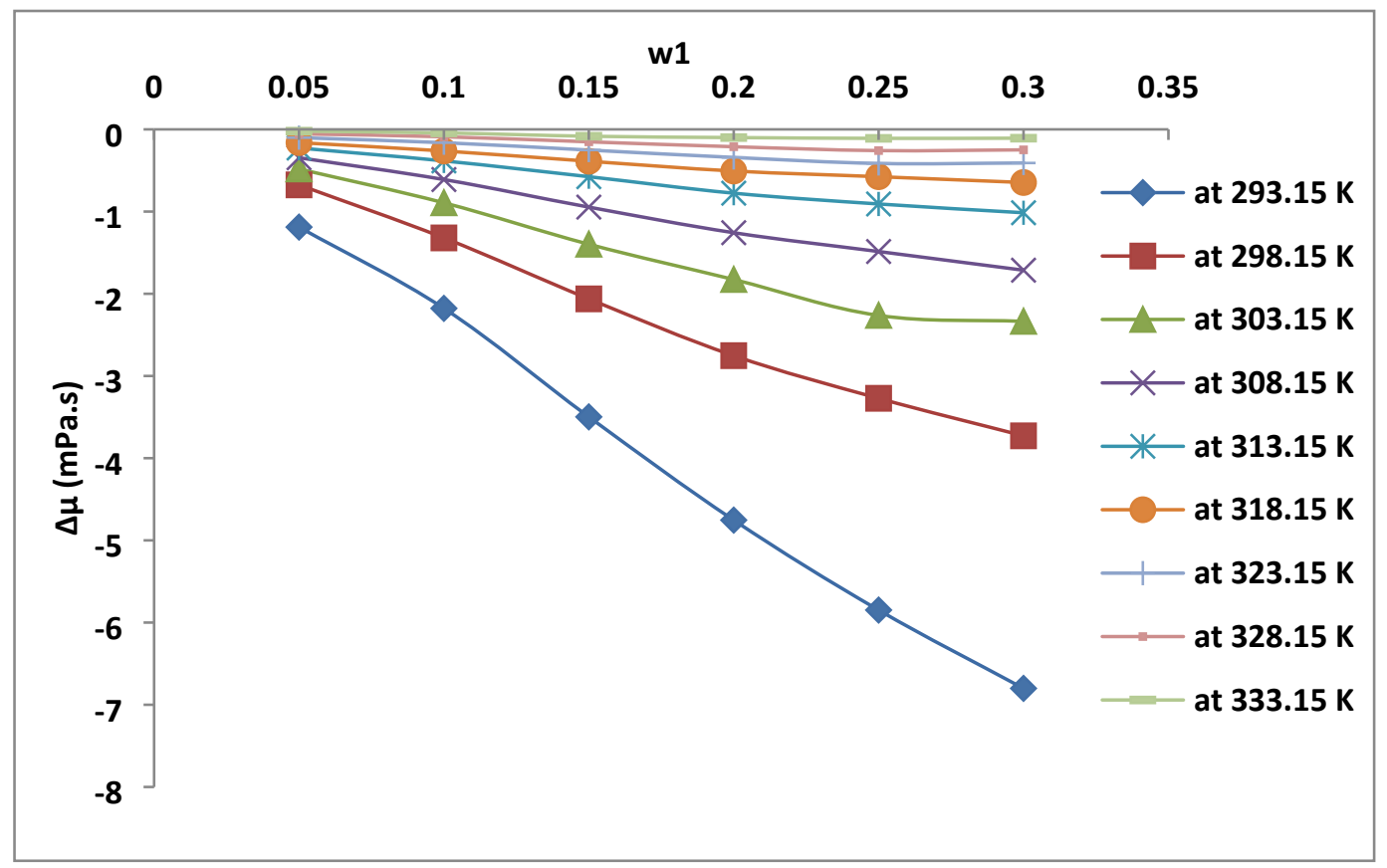

Figure S6. Variation of deviation in viscosity of AEEA with weight fraction of AEEA in the aqueous mixture.

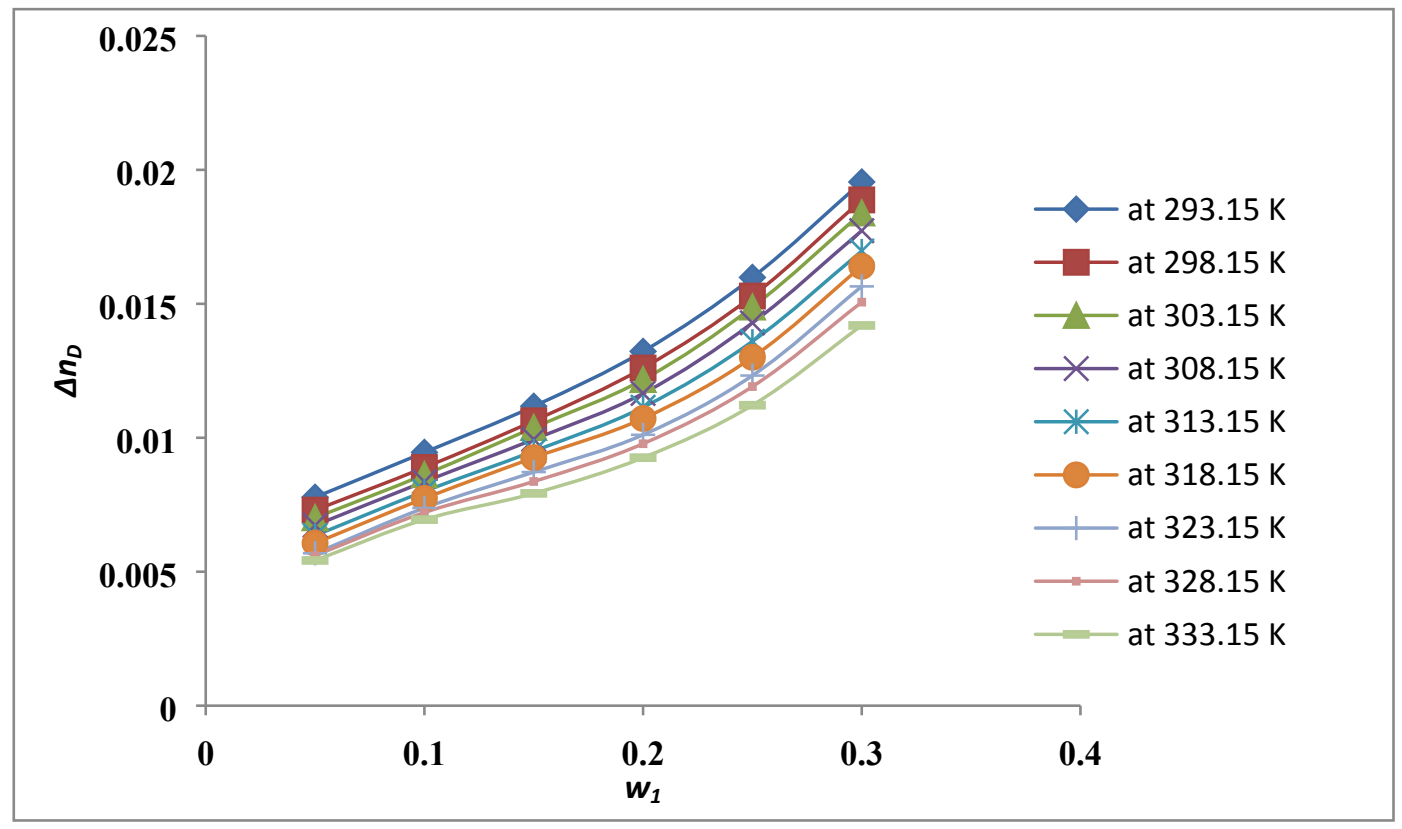

Figure S7. Variation of deviation in the refractive index of MAE with weight fraction of MAE in the aqueous mixture. 


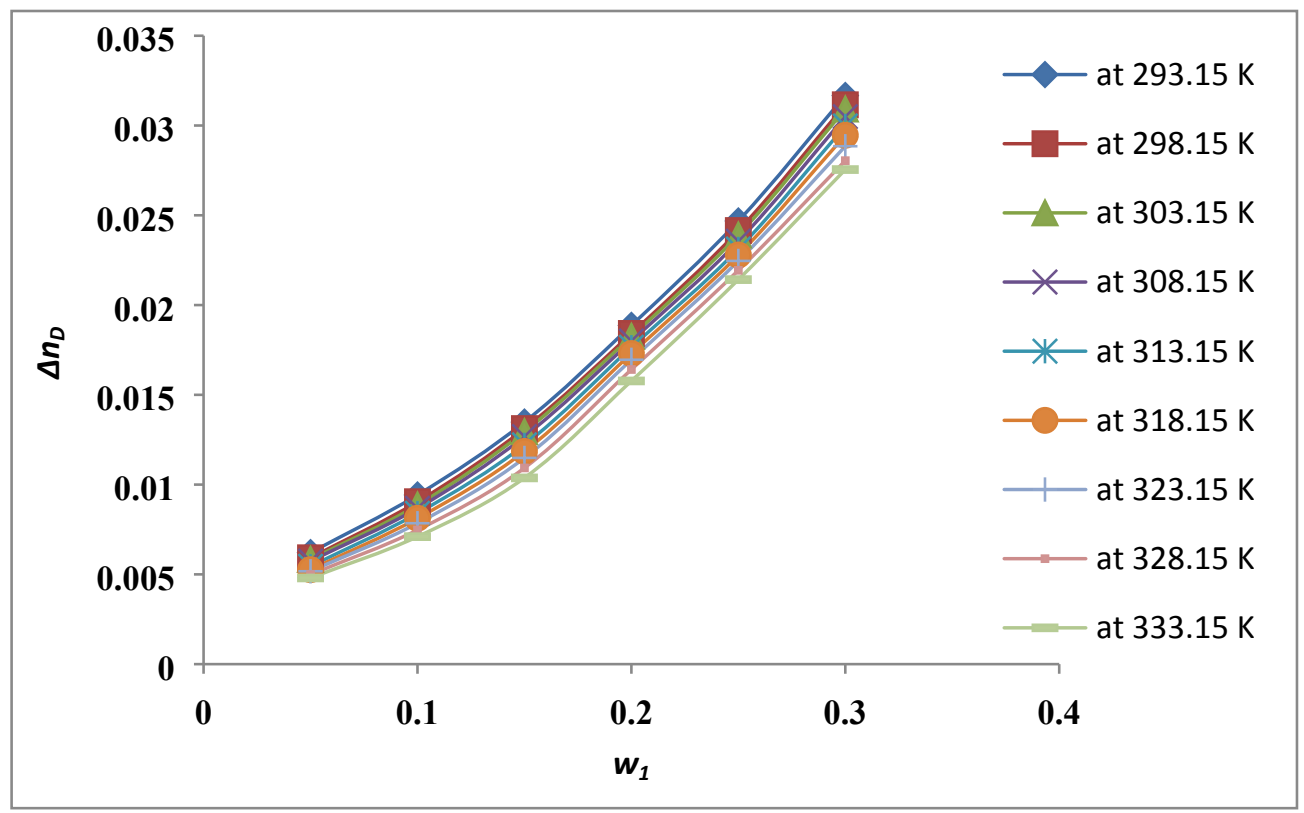

Figure S8. Variation of deviation in the refractive index of AEEA with weight fraction of AEEA in the aqueous mixture.

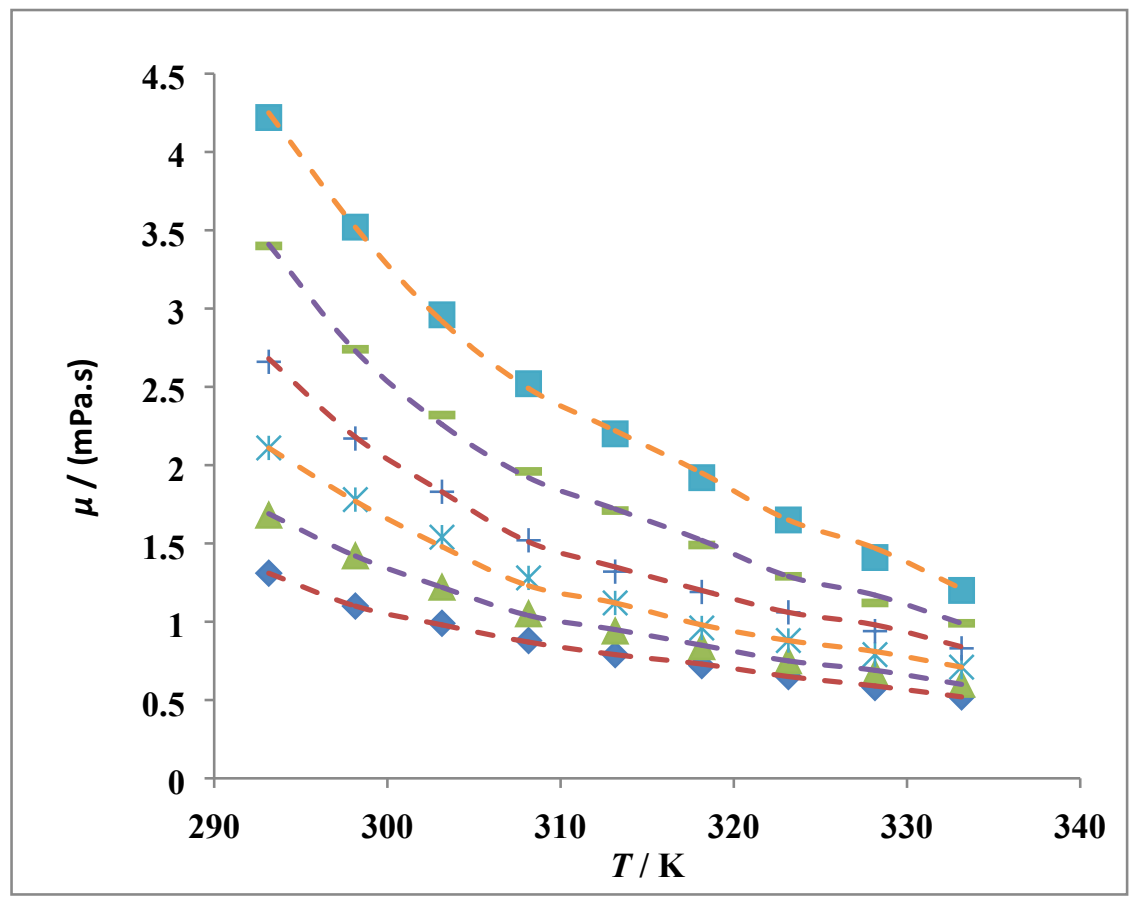

Figure S9. Viscosity of aqueous MAE versus temperature for different weight fraction of MAE; $\checkmark$ for $\mathrm{w}_{1}=0.05 ; \Delta$ for $\mathrm{w}_{1}=0.10 ; *$ for $\mathrm{w}_{1}=0.15 ;+$ for $\mathrm{w}_{1}=0.20 ;-$ for $\mathrm{w}_{1}=0.25 ;$ a for $\mathrm{w}_{1}=0.30$; and dashed lines were found out by Redlich-Kister equation. 


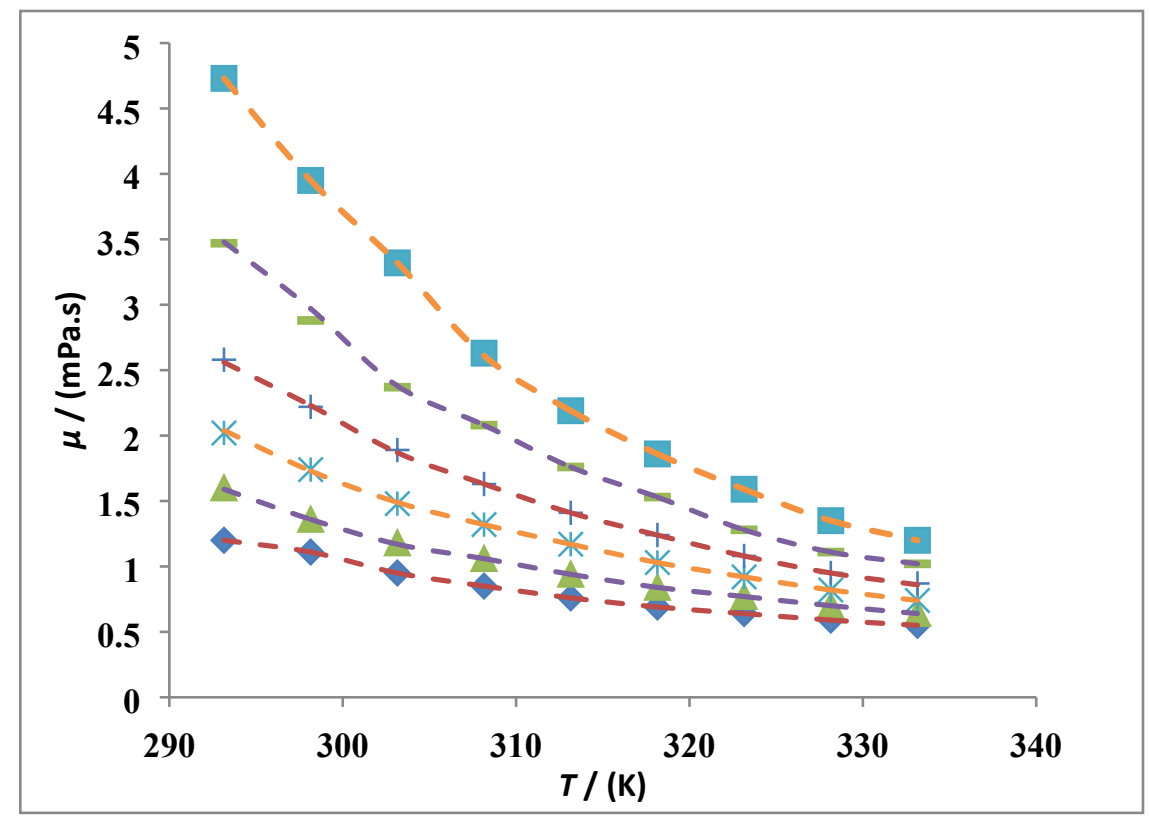

Figure S10. Viscosity of aqueous AEEA versus temperature for different weight fraction of AEEA; $\forall$ for $\mathrm{w}_{1}=0.05 ; \Delta$ for $\mathrm{w}_{1}=0.10 ; *$ for $\mathrm{w}_{1}=0.15 ;+$ for $\mathrm{w}_{1}=0.20 ;-$ for $\mathrm{w}_{1}=0.25 ; \square$ for $\mathrm{w}_{1}$ $=0.30$; and dashed lines were found out by Redlich-Kister equation.

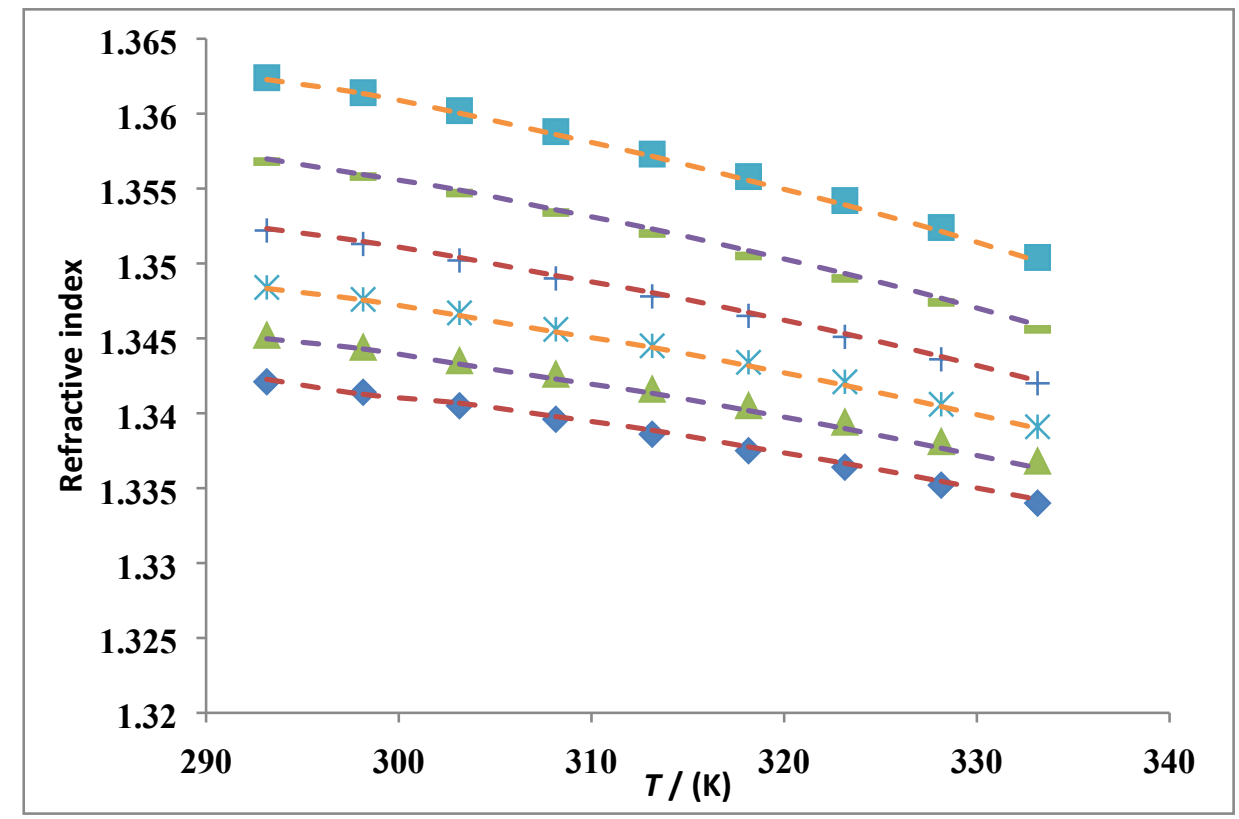

Figure S11. Refractive index of aqueous MAE versus temperature for different weight fraction of MAE; $\checkmark$ for $\mathrm{w}_{1}=0.05 ; \Delta$ for $\mathrm{w}_{1}=0.10 ; *$ for $\mathrm{w}_{1}=0.15 ;+$ for $\mathrm{w}_{1}=0.20 ;-$ for $\mathrm{w}_{1}=0.25 ;$ a for $\mathrm{w}_{1}$ $=0.30$; and dashed lines were found out by Redlich-Kister equation. 


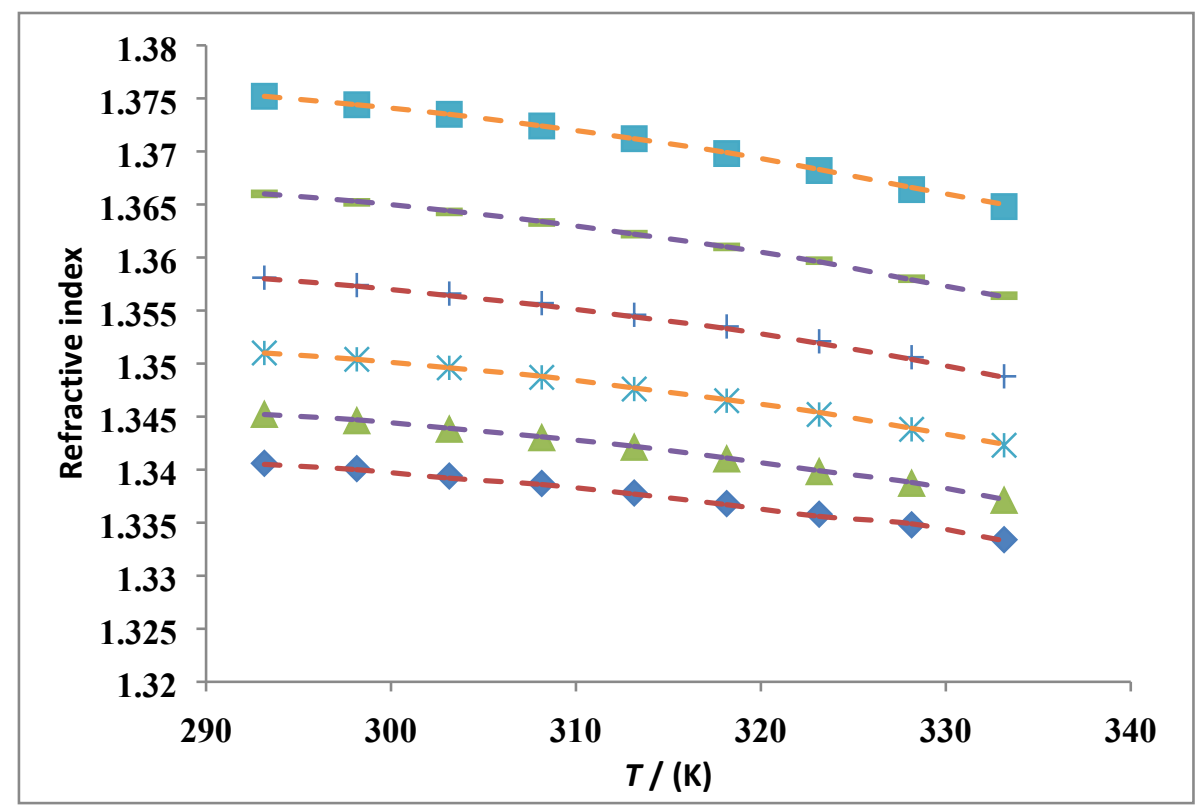

Figure S12. Refractive index of aqueous AEEA versus temperature for different weight fraction of AEEA; $\checkmark$ for $\mathrm{w}_{1}=0.05 ; \Delta$ for $\mathrm{w}_{1}=0.10 ; *$ for $\mathrm{w}_{1}=0.15 ;+$ for $\mathrm{w}_{1}=0.20 ;-$ for $\mathrm{w}_{1}=0.25$; - for $\mathrm{w}_{1}=0.30$; and dashed lines were found out by Redlich-Kister equation. 